\title{
Os modos de vida dos agricultores pluriativos nas aldeias minhotas do noroeste de Portugal
}

\author{
The way of life of pluriactivity farmers in Minho villages in Northwest Portugal
}

\begin{abstract}
Ana Louise de Carvalho Fiúza ${ }^{I^{*}}$ Neide Maria de Almeida Pinto ${ }^{\text {II }}$ Gustavo Bastos Braga ${ }^{\mathrm{I} \text {,II }}$
\end{abstract}
RESUMO

Este artigo teve por objetivo analisar o modo de vida do agricultor pluriativo, uma categoria em expansão na agricultura praticada não apenas nas aldeias minhotas do noroeste de Portugal, lócus deste estudo, mas em grande parte do mundo ocidental. Utilizouse a aplicação de um survey, cross-sectional, aplicado a famílias de agricultores exclusivamente agrícolas e pluriativos, em $50 \%$ das freguesias da vila escolhida para este estudo. Os resultados da pesquisa revelaram a urbanização do modo de vida dos agricultores pluriativos e inclusive dos que viviam exclusivamente da agricultura, apontando, contudo, para a compatibilidade da agricultura com este modo de vida mais tecnologizado e integrado à dinâmica das vilas e cidades.

Palavras-chave: modo de vida, rural, Noroeste de Portugal.

\section{ABSTRACT}

This article aimed to analyze the lifestyle of the pluriactive farmer. This is a growing category in the agricultural practices not only held in the Minho villages in northwestern Portugal, which is the locus for this study, but also vastly found in the eastern world. A cross-sectional survey was conducted, which was applied exclusively to pluriactive, agricultural families, in 50\% of the civil parishes of the chosen village. The results of this research made evident the urbanization in the lifestyle of the pluriactive farmer including those who used to live solely off agriculture. However, this study points out to the compatibility of agriculture with a lifestyle that is more technological, more integrated with the village and the city dynamics.

Key words: lifestyle, rural, northwestern Portugal.

\section{INTRODUÇÃO}

O objetivo deste artigo foi o de analisar o modo de vida dos agricultores pluriativos, que vivem nas aldeias minhotas do noroeste de Portugal. A escolha se justifica pelo fato de que há décadas se acentuou, nesta região, o estreitamento do mercado de trabalho e de produtos, entre as aldeias, as vilas e as cidades. A aproximação espacial entre as aldeias, as vilas e as cidades aproximou os agricultores do mercado de trabalho citadino. Embora se trate de um caso específico, a partir dele, pode-se vislumbrar o lugar que a agricultura passa a ocupar na vida dos agricultores pluriativos, categoria que cresce nos dias atuais, como afirma SILVA (2013). Ao se observar as transformações da agricultura portuguesa entre os anos de 1960 e 2010, percebe-se que, nestas cinco décadas, houve uma rápida e drástica transformação não apenas no tocante à agricultura praticada, como, também, em relação ao modo de vida dos agricultores. Contudo, enquanto os estudos referentes à estrutura agrária e produtiva abundam, nomeadamente, no campo da economia e da sociologia, as questões relativas ao lugar desta agricultura pluriativa na vida e no cotidiano dos agricultores pluriativos tem ficado subsumidos a poucos estudos, dispersos desde a década de 80 aos dias atuais, tal como pode ser visto nos trabalhos de CAVACO (1980), ALMEIDA (1986); CEPEDA (1988); SILVA (1991, 1994, 2013); dentre outros.

No que diz respeito ao aspecto produtivo e censitário da agricultura portuguesa, percebe-se, segundo SILVA (2013), uma contínua diminuição no

\footnotetext{
'Programa de Pós-graduação em Extensão Rural, Departamento de Economia Rural, Universidade Federal de Viçosa (UFV), 36570-000, Viçosa, MG, Brasil. E-mail: louisefiuza@ufv.br. *Autor para correspondência.

IIPrograma de Pós-graduação em Economia Doméstica, UFV, Viçosa, MG, Brasil.

${ }^{\mathrm{III} U n i v e r s i d a d e ~ d o ~ M i n h o ~(U M), ~ C o s t a ~ V e r d e, ~ M i n h o, ~ P o r t u g a l . ~}$ 
número das explorações agrícolas, que se reduziram quase pela metade em quarenta anos: de 1954 a 1994 as explorações agrícolas passaram de 853.568 para 446.146. Quando se observa, especificamente, a região do Minho, no noroeste de Portugal, lócus deste estudo, percebe-se, claramente, as marcas da urbanização da sociedade rural. Nesta região, até fins dos anos 70, era expressiva a presença de camponeses, que viviam da agricultura de subsistência, em suas aldeias. Hoje, os aldeãos minhotos se incorporam, de forma crescente, ao mercado de trabalho e de consumo, inclusive, de alimentos. Tal realidade segue uma tendência mundial, também apontada por SILVA (2013), em relação à diminuição da população ativa na agricultura, em Portugal, que, em 1979, estava próxima de $50 \%$, caindo, em 2010, para $10 \%$. A questão de investigação trabalhada neste artigo está relacionada, justamente, à busca por compreender as mudanças no modo de vida do agricultor pluriativo, uma categoria em expansão na agricultura praticada não apenas nas aldeias minhotas do noroeste de Portugal, mas em grande parte do mundo ocidental.

$\mathrm{O}$ enquadramento teórico utilizado nesta pesquisa articulou-se mediante a utilização de dois conceitos chave para a análise dos dados aqui apresentados: os conceitos de pluriatividade e de modos de vida. Como o objetivo deste estudo foi basicamente o de descrever as condições de vida dos agricultores minhotos, em um ambiente de estreitamento face ao mercado de trabalho e de consumo com as vilas e cidades, adotou-se, neste trabalho, o conceito de pluriatividade de CARNEIRO (2006, 2012). Segundo a autora, a pluriatividade não se constitui apenas na combinação de atividades agrícolas e não agrícolas, sendo esta característica de contextos marcados pela diversificação socioeconômica.

Para CARNEIRO (2006, 2012), a pluriatividade pressupõe, sim, a combinação de atividades agrícolas e não agrícolas, mas, dentro de um contexto de dinamismo econômico. Assim, propicia um entrelaçamento entre o mercado de consumo e de trabalho entre o campo e a cidade, oportunizando aos indivíduos oriundos de famílias agrícolas trabalharem em atividades não agrícolas e investirem a renda vinda destas atividades, inclusive, na exploração agrícola.

Assim, neste artigo, considerou-se como família pluriativa aquela em que um de seus membros exercia atividade não agrícola fora da unidade de exploração agrícola, visto que o contexto em que as aldeias minhotas estão inseridas é marcado pela forte conexão entre o mercado de trabalho e de produtos com as vilas e cidades. Em derivação desta nomenclatura, adotou-se, para a melhor precisão analítica, a denominação "pluriatividade restrita", quando apenas um indivíduo realizava atividades não agrícolas fora da exploração agrícola e "pluriatividade ampla", quando mais de um membro exercia atividade não agrícola fora da propriedade. Ou seja, a nomenclatura aqui proposta se volta para valorizar os efeitos das atividades não agrícolas, realizadas fora da exploração agrícola, sobre os "modos de vida" dos agricultores.

Segundo GUERRA (1993), pode-se conceber "modo de vida" como a exteriorização por parte do indivíduo, das escolhas por ele realizadas mediante as influências recebidas da cultura urbana e/ou rural, e que lhe possibilita "autonomia relativa" para tecer a sua identidade. Considerando inicialmente o aspecto macroestrutural que atua sobre o campo de possibilidades de posicionamento dos indivíduos, diferentes autores, desde o Pós-Segunda Guerra Mundial, vêm apontando para a força expansiva da cultura urbana sobre a sociedade em geral, tanto nas cidades, como nas vilas, aldeias e no campo, tais como: ENDRICH (2010), CARLOS (2004), MCCRACKEN (2003), FEATHERSTONE (1991), WIRTH (1979), LEFEBVRE (2008), RAMBAUD (1973), dentre muitos outros. Tais autores apontam, a partir de diferentes pontos de vista, o fato de que a imagem da cidade, do trabalho e da educação vem modificando profundamente a sociedade rural. Principalmente, os jovens e as mulheres tendem a manifestarem uma abertura maior para as influências advindas da cultura urbana, em função de as avaliarem de forma mais positiva, sobretudo, devido à sobrecarga de trabalho no campo e aos costumes relativos à herança do patrimônio familiar.

Dessa forma, segundo a perspectiva teórica destes diferentes autores, a sociedade se urbaniza de forma crescente, orientando os indivíduos, as suas atitudes e os seus comportamentos segundo as influências advindas da cultura urbana. Consoante a este fenômeno de expansão da cultura urbana, campo e cidade permanecem manifestando diferenças físicas, mas o modo de vida entre ambos os espaços se aproxima, ainda que as peculiaridades indenitárias de cada espaço se modifiquem, direcionadas pelas escolhas realizadas pelas pessoas que vivem nestas diferentes localidades.

\section{MATERIAL E MÉTODOS}

Os procedimentos metodológicos utilizados para analisar os modos de vida dos agricultores pluriativos, que vivem nas aldeias 
minhotas do noroeste de Portugal, foram: a aplicação, em cross-section, de um survey, contendo perguntas fechadas e abertas, com homens e mulheres que viviam em unidades agrícolas (Considerou-se como "exploração agrícola" a unidade que utilizava mão de obra e fatores de produção próprios; que produzisse um ou mais produtos agrícolas para a autossustentação e/ou comercialização; e que estivesse localizada em uma aldeia ou no campo) nas aldeias Minhotas no norte de Portugal, mais especificamente, no Concelho (A grafia da palavra "concelho", em Portugal, no sentido de jurisdição administrativa é com a letra "c", por isto ela mesma foi mantida no texto) de Vila Verde, apesar de terem sido realizadas, também, entrevistas em outros concelhos, nomeadamente em Ponte de Lima e Barcelos. O survey constou de três partes com trinta e oito perguntas. As perguntas foram, em sua maior parte, fechadas, priorizando-se a objetividade das respostas. Contudo, em situações em que se considerou importante o aspecto subjetivo em termos da justificativa dada pelo inquirido para uma determinada escolha, ação ou comportamento, abriuse espaço para as respostas abertas.

A primeira parte do survey foi composta por perguntas relativas à estrutura socioeconômica do agregado familiar, privilegiando a coleta de dados relativos às atividades desenvolvidas por cada membro do agregado familiar. A segunda parte do survey constou de perguntas relativas à estrutura física da casa, às condições de moradia e de trabalho na exploração agrícola. Levantaram-se dados relativos aos eletrodomésticos e utensílios existentes na casa, bem como aos instrumentos e tecnologias utilizadas no trabalho agrícola. Na terceira parte do survey, buscou-se coletar dados relativos ao modo de vida dos entrevistados. Assim, foram levantadas informações relativas ao uso que faziam dos bens de consumo duráveis, como carro, moto e bicicleta, assim, como dos aparelhos relacionados às tecnologias da informação e comunicação, como telemóvel (celular), computador e internet. Foram feitas, ainda, perguntas relativas às atividades de lazer e ao tempo que dedicavam ao não trabalho, privilegiando, neste aspecto, as questões de gênero.

No que diz respeito à amostra, esta foi composta buscando-se caracterizar os três tipos de explorações agrícolas, que importavam à pesquisa: $\left.1^{\circ}\right)$ as explorações exclusivamente agrícolas; $2^{-}$) as explorações pluriativas restritas; e $3^{\circ}$ ) as explorações amplamente pluriativas. Escolheu-se, como local para a realização da pesquisa, o município de Vila Verde, bem como algumas freguesias no seu entorno, em função de ser esta uma região de forte tradição agrícola. Das 48 freguesias que compunham o município de Vila Verde, foram aplicados questionários em 24 delas, ou seja, em 50\% do total. Além destas freguesias, foram aplicados questionários em outras 11 freguesias do entorno de Vila Verde, nomeadamente, em: Amares, Barcelos e Ponte de Lima. Assim, foram aplicados 66 questionários: 25 com homens e 41 com mulheres, tendo sido esta distribuição uma decorrência da disponibilidade do respondente. Os questionários aplicados foram distribuídos quase que igualmente entre os três tipos de explorações agrícolas priorizadas, sendo entrevistados 23 indivíduos, caracterizados como amplamente pluriativos, 20 como pluriativos restritos e 23 como exclusivamente agrícolas.

Uma característica das explorações agrícolas do norte de Portugal é a sua pequena dimensão. Oitenta e dois por cento das explorações agrícolas, nas quais foram aplicados os questionários, não possuíam mais do que 5 ha. As famílias exclusivamente agrícolas destacavam-se entre as que possuíam mais de 5 ha. Já no que diz respeito à idade dos entrevistados, a média foi de 55 anos, tendo sido para os homens 58,2 anos e para mulheres 53,5 anos.

Os indivíduos pertencentes às famílias cujos membros trabalhavam exclusivamente com a agricultura tendiam a ser mais velhos. Ou seja, as famílias pluriativas tendiam a ser compostas por indivíduos mais novos, no entanto essa diferença não é comprovada pelo Teste Anova One Way. No que diz respeito à renda, as famílias amplamente pluriativas apresentaram renda maior: 61\% ganhavam acima de novecentos Euros (EU\$ 900,00), enquanto, nas demais famílias, $64 \%$ ganhavam menos do que este valor. No entanto, em termos estatísticos, não se pode associar renda e pluriatividade, uma vez que o Teste de Qui-quadrado de Pearson nessas variáveis apresentou um p-valor de 0,748 .

Finalizando a caracterização da amostra, cabe destacar que, no tocante à escolaridade, os homens estudaram, em média, mais que as mulheres: 8,77 anos contra 6,97, diferença, contudo, estatisticamente não significante a $5 \%$ pelo teste $\mathrm{T}$ de médias. Isso leva a crer que já não é tão evidente uma diferença de gênero nesse quesito, o que pode estar a refletir a tendência de maior dedicação ao estudo por parte das mulheres das gerações mais novas.

\section{RESULTADOS E DISCUSSÃO}

Quanto aos modos de morar, percebeuse, nas habitações aldeãs minhotas, a marca dos recursos econômicos praticamente inexpressivos 
até fins da década de 70, como demonstra os estudos desenvolvidos por SILVA (1998, 2013). A monetarização da vida econômica adveio tanto do processo migratório para outros países da Europa, como França, Luxemburgo, Alemanha, dentre outros, que se fortaleceu nos anos 80, nomeadamente, por parte dos homens, como, também, no mercado de trabalho das vilas e cidades próximas às aldeias. A partir do afluxo da renda extra-agrícola, as antigas casas de pedra deram lugar às casas modernas e bem equipadas (Tabela 1).

Os dados não mostram fortes discrepâncias em termos das reformas feitas na casa e no terreno entre os três tipos de famílias. Pode-se perceber nas famílias pluriativas, contudo, uma maior importância em relação à reforma da casa, enquanto a reforma do terreno sobressaiu entre as famílias exclusivamente agrícolas. Contudo, não foram significativas estatisticamente as diferenças observadas, de acordo com o teste de Fisher, aplicado nas respectivas variáveis. Já no que diz respeito à relação entre a produção e o consumo de alimentos, observou-se uma tendência à diversificação produtiva entre todos os três tipos de famílias pesquisadas. Em todas elas, mostrou-se relevante a prática agrícola voltada para a autoprodução de legumes, verduras, frutas, vinho e a criação de pequenos animais, como porcos, galinhas, coelhos, patos, cabritos e borregos. Já a criação de gado para corte ou para leite não se sobressaiu em nenhum dos tipos de exploração agrícola pesquisada. Tal fato pode ser explicado pelo tamanho das propriedades, que, em sua esmagadora maioria, 46 propriedades, correspondendo a $70 \%$ da amostra, não tinham mais do que 3 ha. A produção de pão, embutidos e doces de compotas também não se sobressaía em termos das atividades desenvolvidas pelas famílias. Isso poderia indicar uma mudança no modo de vida, em termos do crescimento do consumo de alimentos processados e comprados prontos, mesmo em meio à permanência da importância da carne dos pequenos animais, dos ovos, das hortaliças e da batata para a dieta alimentar (Tabela 1).

Aproximadamente $50 \%$ de todas as famílias pesquisadas compravam até metade daquilo que necessitava para o seu consumo alimentar. Contudo, a compra de alimentos mostrou-se um pouco menor nas famílias exclusivamente agrícolas, conforme pode ser observado nos dados apresentados a seguir, na tabela 2, que apresenta, respectivamente, a variedade do que é produzido e criado pelas famílias pesquisadas, bem como a porcentagem de compra de alimentos (Tabela 2). A associação entre esse padrão de consumo e o tipo de família é comprovado pelo teste de Qui-quadrado de Pearson entre as variáveis que indicam se a família compra ou não até $50 \%$ de seu consumo alimentar e como ela se enquadra na pluriatividade, apresentando um p-valor de 0,007.

Chamou a atenção, ainda, o fato de, apesar de ser associado o tipo de família e se elas compram no máximo até $50 \%$ do que consumiam, tiver diferenças percentuais pequenas. Esta situação pode estar a evidenciar a importância que a agricultura e a criação de pequenos animais continuavam a ter, inclusive, para os agricultores pluriativos. Diante destes dados, pode-se considerar como plausível afirmar que a agricultura permanece presente no cotidiano dos diferentes tipos de famílias, como um traço indenitários comum a elas, independente de serem pluriativas ou exclusivamente agrícolas, estando, contudo, incorporada de diferentes formas e proporções no seu modo de vida. De certa forma, a agricultura minhota parece refletir as estratégias dos aldeãos de resistir e adaptar-se, tal como mostrado por SILVA (1998, 2013), que pesquisou este contexto no período de 1960 a 2010. Tal adaptação pode ser observada em relação às mudanças dos modos de vida, nomeadamente, no que se refere ao padrão de consumo de eletrodomésticos. As casas aldeãs apresentavam, basicamente, os equipamentos comuns em casas citadinas, diferenciando-se destas quanto ao maior uso de lareira na cozinha e de fogão à lenha para aquecimento da água e da casa. Contudo, no que se refere aos percentuais de computador, internet, carro e micro-ondas, estes foram menores nas famílias exclusivamente agrícolas, quando comparado às famílias amplamente pluriativas (Tabela 1), todas essas diferenças são comprovadas pelo teste de Qui-quadrado de Pearson, apresentando p-valor nas associações assinaladas menor que 0,05 .

Tais diferenças, estatisticamente corroboradas, relativas aos bens de consumo duráveis podem estar a indicar um deslocamento no eixo de produção do modo de vida dos pluriativos, em relação aos exclusivamente agrícolas, evidenciando uma maior proximidade dos primeiros em relação à matriz urbano-citadina, enquanto os últimos estariam mais próximos da matriz rural. Estas apresentam um hibridismo maior entre o modo de vida urbano e rural, que as famílias exclusivamente agrícolas. Ao se analisar os dados relativos ao ranking valorativo dos eletrodomésticos, pode-se perceber que a valorização dos eletrodomésticos por parte dos agricultores é afetada pelo tipo de família a que eles pertencem. A tabela de classificação criada pelo Teste de Friedman revelou que o "p-valor era menor que 0,05", o que indica que a valorização atribuída pelos inquiridos 
Tabela 1 - Perfil dos agricultores segundo o tipo de família.

\begin{tabular}{|c|c|c|c|c|}
\hline \multirow{2}{*}{$\frac{\text { CÔMODO }}{\text { REFORMADO }}$} & \multicolumn{4}{|c|}{ } \\
\hline & Amplamente Pluriativa & Pluriativa Restrita & Exclusivamente Agrícola & Total \\
\hline Reforma da casa de banho (banheiro) & $16(69,5 \%)$ & $13(65 \%)$ & $15(65,2 \%)$ & $44(66,6 \%)$ \\
\hline Reforma da cozinha & $16(69,5 \%)$ & $13(65 \%)$ & $14(60,8 \%)$ & $43(65,15 \%)$ \\
\hline Reforma da copa & $14(60,86 \%)$ & $11(55 \%)$ & $12(52,17 \%)$ & $37(56 \%)$ \\
\hline Reforma do quarto do casal & $10(43,47 \%)$ & $13(65 \%)$ & $12(52,17 \%)$ & $35(53,03 \%)$ \\
\hline Reforma do quarto dos filhos & $10(43,47 \%)$ & $12(60 \%)$ & $9(39,13 \%)$ & $31(46,96 \%)$ \\
\hline Reforma do entorno da casa & $10(43,47 \%)$ & $12(60 \%)$ & $11(47,82 \%)$ & $33(50 \%)$ \\
\hline Reforma da garagem & $8(34,78 \%)$ & $5(25 \%)$ & $5(21,73 \%)$ & $18(27,27 \%)$ \\
\hline Reforma do terreno & $13(56,52 \%)$ & $10(50 \%)$ & $16(69,56 \%)$ & $39(59,09 \%)$ \\
\hline \multirow{2}{*}{$\begin{array}{l}\text { ATIVIDADES RELATIVAS AO } \\
\text { CULTIVO E CRIAÇÃO }\end{array}$} & - & ----TIPOS DE FA & 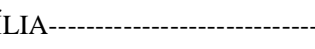 & --------------- \\
\hline & Amplamente Pluriativa & Pluriativa Restrita & Exclusivamente Agrícola & Total \\
\hline Cultivo de feijão verde & $21(91 \%)$ & $17(85 \%)$ & $23(100 \%)$ & $61(92 \%)$ \\
\hline Cultivo de batata & $21(91 \%)$ & $19(95 \%)$ & $20(87 \%)$ & $60(91 \%)$ \\
\hline Criação de pequenos animais & $19(83 \%)$ & $18(90 \%)$ & $23(100 \%)$ & $60(91 \%)$ \\
\hline Cultivo de frutas & $20(87)$ & $13(57 \%)$ & $19(83 \%)$ & $52(79 \%)$ \\
\hline Lavoura de milho & $16(70 \%)$ & $13(57 \%)$ & $17(74 \%)$ & $4670 \%$ \\
\hline Produção de vinho & $12(52 \%)$ & $13(65 \%)$ & $14(61 \%)$ & $39(59 \%)$ \\
\hline Cultivo de abóbora & $12(52 \%)$ & $9(45 \%)$ & $15(65 \%)$ & $36(55 \%)$ \\
\hline Cultivo de flor & $14(61 \%)$ & $10(50 \%)$ & $12(52 \%)$ & $36(55 \%)$ \\
\hline Venda de animais & $11(48 \%)$ & $8(40 \%)$ & $10(34 \%)$ & $29(44 \%)$ \\
\hline Venda de produtos cultivados & $10(43 \%)$ & $6(30 \%)$ & $11(48 \%)$ & $27(41 \%)$ \\
\hline Produção de pão & $6(27 \%)$ & $2(10 \%)$ & $12(52 \%)$ & $20(30 \%)$ \\
\hline Cultivo de prado & $5(22 \%)$ & $4(20 \%)$ & $10(43 \%)$ & $19(29 \%)$ \\
\hline Criação de vaca & $6(26 \%)$ & $5(25 \%)$ & $7(30 \%)$ & $18(27 \%)$ \\
\hline Produção de embutidos & $5(22 \%)$ & $3(15 \%)$ & $7(30 \%)$ & $15(23 \%)$ \\
\hline Venda de produtos caseiros & $5(22 \%)$ & $3(15 \%)$ & $6(26 \%)$ & $14(21 \%)$ \\
\hline Cultivo de oliveiras & $4(17 \%)$ & $5(25 \%)$ & $3(13 \%)$ & $12(18 \%)$ \\
\hline Produção de doces em compota & $5(22 \%)$ & $1(5 \%)$ & $3(13 \%)$ & $9(14 \%)$ \\
\hline BENS DE CONSUMO DURÁVEIS & Amplamente Pluriativa & $\begin{array}{l}\text { Pluriativa Restrita } \\
\text { Pl---TIPOS DE FA }\end{array}$ & Exclusivamente Agrícola & Total \\
\hline Frigorífico (Geladeira) & $23(100 \%)$ & $20(100 \%)$ & $23(100 \%)$ & $66(100 \%)$ \\
\hline Fogão a gás & $23(100 \%)$ & $20(100 \%)$ & $23(100 \%)$ & $66(100 \%)$ \\
\hline Rádio & $23(100 \%)$ & $19(95 \%)$ & $22(96 \%)$ & $64(97 \%)$ \\
\hline Máquina de lavar roupa & $23(100 \%)$ & $20(100 \%)$ & $18(78 \%)$ & $61(92 \%)$ \\
\hline Rádio & $22(96 \%)$ & $17(85 \%)$ & $22(96 \%)$ & $61(92 \%)$ \\
\hline Telemóvel (Celular) & $23(100 \%)$ & $20(100 \%)$ & $16(70 \%)$ & $59(89 \%)$ \\
\hline Aspirador de pó & $22(96 \%)$ & $19(95 \%)$ & $17(74 \%)$ & $58(88 \%)$ \\
\hline Carro & $23(100 \%)$ & $19(95 \%)$ & $12(52 \%)$ & $54(82 \%)$ \\
\hline Micro-ondas & $21(91 \%)$ & $19(95 \%)$ & $13(57 \%)$ & $53(80 \%)$ \\
\hline Lareira para cozinhar & $15(65 \%)$ & $14(70 \%)$ & $20(87 \%)$ & $49(74 \%)$ \\
\hline Computador & $22(96 \%)$ & $16(80 \%)$ & $9(39 \%)$ & $47(71 \%)$ \\
\hline Telefone fixo & $16(70 \%)$ & $12(60 \%)$ & $16(70 \%)$ & $44(67 \%)$ \\
\hline Internet & $19(83 \%)$ & $15(75 \%)$ & $8(35 \%)$ & $42(64 \%)$ \\
\hline Fogão à lenha & $14(61 \%)$ & $12(60 \%)$ & $13(57 \%)$ & $39(59 \%)$ \\
\hline Mota (Moto) & $9(39 \%)$ & $10(50 \%)$ & $10(43 \%)$ & $29(44 \%)$ \\
\hline Canal pago & $9(39 \%)$ & $6(30 \%)$ & $4(17 \%)$ & $19(29 \%)$ \\
\hline
\end{tabular}

Fonte: Dados da pesquisa, 2013. 
Tabela 2 - Tabulação cruzada entre o tipo de família e a \% das necessidades de consumo.

Amplitude das necessidades de consumo

\begin{tabular}{|c|c|c|c|c|c|}
\hline & & $\begin{array}{l}\text { Compra no máximo } 50 \% \text { do } \\
\text { que consome }\end{array}$ & $\begin{array}{l}\text { Compra entre } \\
50 \% \text { e } 60 \% \text { do } \\
\text { que consome }\end{array}$ & $\begin{array}{l}\text { Compra mais do } \\
\text { que } 60 \% \text { do que } \\
\text { consome }\end{array}$ & Total \\
\hline \multirow{3}{*}{$\begin{array}{l}\text { Tipo de família } \\
\text { segundo atividade }\end{array}$} & Pluriatividade ampla & $11(48 \%)$ & $4(17 \%)$ & $8(35 \%)$ & 23 \\
\hline & Pluriatividade restrita & $10(50 \%)$ & $5(25 \%)$ & $5(25 \%)$ & 20 \\
\hline & Exclusivamente agrícola & $13(57 \%)$ & $3(13 \%)$ & $7(30 \%)$ & 23 \\
\hline Total & & $34(52 \%)$ & $12(18 \%)$ & $20(30 \%)$ & 66 \\
\hline
\end{tabular}

Fonte: Dados da pesquisa, 2013.+

não seguia a mesma ordem, sendo afetada pelo tipo de família na qual o inquirido está inserido. Dito de outra forma, a hierarquia estabelecida em termos de valorização dos eletrodomésticos era afetada pelo tipo de família a qual o inquirido pertencia.

A maior valorização do computador e da internet entre as famílias "amplamente pluriativas" em comparação com as "exclusivamente agrícolas" não significa que estas últimas não estejam incorporando esta influência, mas, antes de tudo, indica que o ritmo com que o fazem é mais lento, possivelmente em função da média de idade destas famílias ser maior e a escolaridade e a renda serem menores. Contudo, as diferenças percentuais relativas à avaliação dos eletrodomésticos entre as famílias "amplamente pluriativas" e as "exclusivamente agrícolas", estão a mostrar uma assimilação destas tecnologias e refletem, antes de tudo, um ritmo diferenciado de incorporação dos artefatos tecnológicos, mais do que a sua simples rejeição.

\section{CONSIDERAÇÕES FINAIS}

Ao se analisar os modos de vida nas famílias dos agricultores pluriativos (amplos e restritos) nas aldeias minhotas, perceberam-se dois fenômenos que estão por se consolidar no noroeste português: a existência de agricultura sem agricultor em tempo integral e a urbanização dos modos de vida dos agricultores. Se, por um lado, é inegável a forma como o modo de vida destes agricultores pluriativos ou não se urbanizou, nomeadamente, no que se refere ao padrão de moradia, a posse e uso de eletrodomésticos e das tecnologias da informação e comunicação, bem como dos meios de transporte próprio. Por outro lado, a agricultura permanece presente na vida destes agricultores e se mostra adaptada a estas mudanças.

Aproximadamente metade das famílias entrevistadas produzia cerca de $50 \%$ dos alimentos que consumia, nomeadamente, hortaliças, frutas, legumes, pequenos animais, ovos e vinho. Ou seja, produziam o que é possível se produzir em terrenos de reduzida dimensão, em que cerca de $80 \%$ não possuía mais do que 5 ha de terra, mas grande parte destes, nem mesmo 1 ha possuía.

Assim, o que as transformações no modo de vida dos agricultores minhotos do noroeste de Portugal parecem mostrar, sem dúvida, é que a agricultura pode se adaptar à urbanização dos modos de vida e mesmo existir sem agricultores full-time. A tecnologia, o uso de máquinas e implementos agrícolas foram avaliados pelos agricultores familiares minhotas como fundamentais para a continuidade do trabalho agrícola. Assim, como a proximidade das vilas e cidades foi percebida como um fator de estímulo para a continuidade das práticas agrícolas, haja vista os benefícios econômicos para a agricultura advindos da inserção dos membros da família no mercado de trabalho. Ou seja, a agricultura pode, sim, ter deixado de definir os status indenitários daquele que com ela trabalha, mas ela continua a existir e a ser determinante para a reprodução, não apenas das famílias de agricultores exclusivamente agrícola, mas, também, dos pluriativos. Estes têm um modo de vida urbanizado, a agricultura se mostra perfeitamente compatível com ele. Se ela não é mais pungente econômica e produtivamente, isto se deve, certamente, a ser esta região do Minho marcada pela existência de minifúndios e pelo fato de Portugal ter optado por uma política agrícola que incentiva a agricultura de escala comercial em detrimento da agricultura de pequena escala.

\section{AGRADECIMENTOS}

A realização deste trabalho só foi possível graças ao suporte financeiro do Conselho Nacional de Desenvolvimento Científico e Tecnológico $(\mathrm{CNPq})$ que concedeu uma Bolsa de Pós-Doutorado (Processo 236852/2012-4); ao Departamento de Economia Rural da Universidade Federal de Viçosa e, por fim, agradecemos à Profa. Dra. Maria Johanna Schouten, supervisora da pesquisa de Pós-Doutoramento. 


\section{REFERÊNCIAS}

ALMEIDA, J.F. Classes sociais nos campos. Camponeses parciais numa região do noroeste. Lisboa: Instituto de Ciências Sociais da Universidade de Lisboa, 1986. p. 86.

CARLOS, Ana Fani Alessandri. Seria o Brasil "menos urbano do que se calcula"? In: O espaço urbano: novos escritos sobre a cidade. São Paulo: Contexto, 2004. p. 129-136.

CARNEIRO, M.J. Pluriatividade da agricultura no Brasil: uma reflexão crítica. In: SCHNEIDER, S. (Org.). A diversidade na agricultura familiar. Porto Alegre:UFRGS, 2006. p.296

CARNEIRO, M.J. Ruralidades contemporâneas: modos de viver e pensar o rural na sociedade brasileira. Rio de Janeiro: Mauad X, 2012. p. 268 .

CAVACO, C. A agricultura a tempo parcial. Lisboa: Centro de Estudos Geográficos, 1980. p.41.

CEPEDA, F.J.T. Emigração, regresso e desenvolvimento no nordeste interior português.Vila Real: Universidade de Trás-osMontes e Alto Douro, 1988. p.473.

ENDRICH, Â. Perspectivas sobre o urbano e o rural. In: SPOSITTO, M. et al. Cidade e campo: Relações e contradições entre urbano e rural. São Paulo: Expressão Popular, 2010. p.247.
GUERRA, I. Modos de vida. Novos percursos e novos conceitos. Sociologia problemas e práticas, n.13, p.59-74, 1993.

FEATHERSTONE, M. Consumer culture and postmodernism. London: Sage, (1991). p.203.

LEFEBVRE, H. A revolução urbana. Belo Horizonte: UFMG, 2008. p.178.

McCRACKEN, G. Cultura e consumo. Rio de Janeiro: Mauad, (2003). p.208.

RAMBAUD, P. Société rurale et urbanisation. Paris: Editions du Seuil,1973. p.343.

SILVA, M.C. Casa e casas em espaço rural minhoto: o poder doméstico. Cadernos do Noroeste, v.4,n.6-7,p.79-99, 1991.

SILVA, M.C. Resistir e adaptar. Constrangimentos e estratégias camponeses no Noroeste de Portugal. Porto: Edições afrontamento, 1998. p.479.

SILVA, M.C. Socio-antropologia rural e urbana: Fragmentos da sociedade portuguesa (1960-2010). Porto: Afrontamento, 2013. p.304.

WIRTH, L. O urbanismo como modo de vida. In: VELHO, O.G.O. Fenômeno urbano. 4.ed. Rio de Janeiro: Zahar, 1979. p.90-113. 